\title{
The TEDS-M: Important Issues, Results and Questions
}

\author{
Konrad Krainer, Feng-Jui Hsieh, Ray Peck and Maria Teresa Tatto
}

\begin{abstract}
Until the last decade, international comparative studies in mathematics education focused primarily on the knowledge and beliefs of school students. Recently, the focus has shifted towards research on teachers and teacher education. The Teacher Education and Development Study in Mathematics (TEDS-M) is the first international large-scale study about (initial primary and secondary) mathematics teacher education with 17 countries participating. The importance of largescale research in mathematics teacher education is mirrored in the decision to organize a Plenary Panel on TEDS-M at the 12th International Congress on Mathematical Education (ICME-12). This paper sketches the background of the study, main program features and major inputs of the Plenary Panel.
\end{abstract}

Keywords Mathematics teacher education - Content knowledge - Pedagogical content knowledge $\cdot$ Survey research - International and comparative studies

K. Krainer $(\bowtie)$

Alpen-Adria-Universität Klagenfurt, Klagenfurt, Austria

e-mail: konrad.krainer@aau.at

F.-J. Hsieh

National Taiwan Normal University, Taipei, Taiwan

e-mail: hsiehfj@math.ntnu.edu.tw

R. Peck

Australian Council for Educational Research, Sydney, Australia

e-mail: peck@acer.edu.au

M.T. Tatto

Michigan State University, Michigan, USA

e-mail: mttatto@msu.edu

(C) The Author(s) 2015 


\section{Introduction}

Empirical research over recent decades points to the high influence of teachers on students' learning of mathematics. Teachers have been identified as key agents of educational change (Fullan 1993; Krainer 2011). Amongst others, the comprehensive meta-analysis on student learning by Hattie (2003) found that teachers' impact on students' learning is high. Identified factors that contribute to major sources of variation in student performance include the students $(50 \%)$ and teachers $(30 \%)$ as the most important factors, whereas home, schools, principals, peer effects (altogether $20 \%$ ) play a less important role.

Thus intensive research in mathematics teacher education is needed. There is increasing literature about relevant results, however, large-scale findings about the conditions, processes, and effects of mathematics teacher education are rare (Adler et al. 2005). Since Mathematical Content Knowledge (MCK) and Mathematical Pedagogical Content Knowledge (MPCK) play a fundamental role for teachers' effectiveness (Shulman 1986; Baumert et al. 2010), the education of future teachers is a crucial phase in teachers' professional development and a key time for communicating pedagogical innovations, especially because many teachers tend to teach as they have been taught.

The Teacher Education and Development Study in Mathematics (TEDS-M) is the first cross-national data-based study about initial mathematics teacher education with large-scale samples (Tatto et al. 2011, 2012; Loewenberg-Ball et al. 2012). The study collected data from 23,000 future mathematics teachers (primary and lower-secondary) from 17 countries $^{1}$ in 2008-2009.

The TEDS-M study drew nationally representative samples and conducted large scale surveys of teacher education institutions, teacher educators, and future teachers to provide substantive information on how institutions organize and prepare future teachers to teach mathematics at the primary and secondary levels. The study also successfully created instruments for measuring the MCK and MPCK of future teachers at the international level in different types of program groups.

TEDS-M was a collaborative effort of worldwide institutions, launched by the International Association for the Evaluation of Educational Achievement (IEA) to address concerns raised by the Third International Mathematics and Science Study (TIMSS). The study is an ambitious attempt to move the study of teacher education and its outcomes in the direction of scientific research with the goal to inform policy. The study was directed by Michigan State University (MSU) in collaboration with the Australian Council for Educational Research (ACER), and National Research Centres in all 17 countries and received important funding from the National Science Foundation (USA), and the IEA.

\footnotetext{
${ }^{1}$ Botswana, Canada (was unable to meet IEA sampling requirements), Chile, Chinese Taipei (Taiwan), Georgia, Germany, Malaysia, Norway, Philippines, Oman, Poland, Russia, Singapore, Spain, Switzerland, Thailand, and USA.
} 
TEDS-M posed questions at three levels: (a) Policies: What are the teacher education policies of the participating countries that support the mathematics and related knowledge for teaching of their future teachers? (b) Practices: What learning opportunities in teacher education programs allow future teachers to attain mathematics and related knowledge for teaching? (c) Outcomes: What is the level and depth of the mathematics and related knowledge for teaching attained by future teachers at the end of their initial teacher education programs? TEDS-M aimed at bringing these three components - policies, practices and outcomes of mathematics teacher education - together. As a result, the findings should be of interest to educational policy makers and researchers, mathematicians and mathematics educators. In the same way that teachers are the key to educational change in schools, mathematicians and mathematics educators are-together with the future teachers themselves - the key drivers of change and innovation in mathematics teacher education.

Comparisons between countries are complex. Outcomes from the study show significant differences in outcome measures between future teachers in different programs in different countries. Since the participating countries have a diverse level of "human development" (formerly "standard of living"), as measured by the Human Development Index (HDI), ${ }^{2}$ it is important to take this into account when comparing countries performance in TEDS-M. A study by Blömeke (2011, p. 19) shows a close correlation between the countries' TEDS-M outcome measures and their HDI. However, related to this index, some countries achieved higher than expected in TEDS-M, others lower. The Blömeke study indicates Taiwan, Russia, and Thailand as "overachieving" countries and the USA, Norway, and Chile as "underachieving" countries compared to their level of human development. From the case of Taiwan, we will learn what factors may have a positive influence on the education of future mathematics teachers graduating with high levels of MCK and MPCK. We will also see that Chile and Norway, both performing below their expectations compared to HDI, started reforms as a consequence of their TEDS-M results. Thus, this study offers opportunities to compare with other countries, to look for communalities and differences, as well as for (relative) strengths and weaknesses. However, in order to learn more deeply from other countries and probably to take relevant actions fitting to a country's own context, it is important to look in a more detailed way at program characteristics. TEDS-M is both, a starting point for diverse comparisons among countries, as well as a chance to investigate the quality of teacher education programs and the learning opportunities they offer to future teachers of mathematics.

\footnotetext{
2 The HDI is a comparative measure of life expectancy, literacy, education, and standards of living for countries worldwide.
} 


\section{The Organization of the Plenary Panel on TEDS-M}

The Plenary Panel on TEDS-M at ICME-12 involved four Panel Members: FengJui Hsieh (Taiwan), Konrad Krainer (Austria, Chair), Ray Peck (Australia), and Maria Teresa Tatto (USA).

After a short introduction of the Plenary Panel members by Mi-Kyung Ju (Korea, Presider), some basic information about TEDS-M and the Plenary Panel by the chair, the other Panel members gave inputs on the following topics:

- Teaching and teacher knowledge: A focus on MCK and MPCK (Ray Peck)

- Teacher education and quality: The performance of Taiwan in an international context (Feng-Jui Hsieh)

- Research in teacher education and TEDS-M: International findings and implications for future policy research (Maria Teresa Tatto)

In order to support the audience in actively following the presentations, each input included a short activity for the whole audience. Given the fact, that in a Plenary Panel with some thousand people it is not easy to have open discussions, the Panel team invited Audience representatives. They are well-known experts with diverse background (mathematics, mathematics education or pedagogy), some having deeper knowledge about TEDS-M: Deborah Loewenberg Ball (USA), Mellony Graven (South Africa), Maitree Inprasitha (Thailand), Liv Sissel Gronmo (Norway), Leonor Varas (Chile), and Ildar Safuanov (Russia).

The Audience representatives were prepared to respond to questions raised by the chair of the Panel each related to the corresponding topic presented by the three panelists.

\section{Teaching and Teacher Knowledge: A Focus on MCK and MPCK}

\section{Why Is Teacher Knowledge Important?}

Anthony and Walshaw (2009, p. 25) remind us that knowledge helps teachers recognize, and then act upon, the teaching opportunities that come up in the moment. Understanding the 'big ideas' of mathematics, permits teachers to recognize mathematics as a 'coherent and connected system'. This in turn enables them to 'make sense of and manage multiple student viewpoints'. With strong content and pedagogical content knowledge teachers can help students to develop 'mathematically grounded understandings'.

Research into student achievement in mathematics has strongly supported the importance and significance of teacher knowledge. For example, Hill et al. (2005), found that the mathematical knowledge of teachers was significantly related to student achievement gains in both first and third grades after controlling for key student- and teacher-level covariates. 


\section{Defining Teacher Knowledge in TEDS-M}

Teacher knowledge for teaching mathematics in TEDS-M was narrower than that defined by Shulman (1986). It was limited to the knowledge that could be reasonably demonstrated by future teachers in their final year of their programs on a written 60 min assessment. It was also limited to the knowledge that was considered important and culturally meaningful to the 17 participating countries.

In short, the knowledge for teaching mathematics in TEDS-M was confined to two dimensions - mathematics content knowledge (MCK) and mathematics pedagogical content knowledge (MPCK). MCK is mathematics that teachers know and can do whereas MPCK is knowledge about how to assist students to learn mathematics. MPCK is not knowledge that ordinary citizens possess. It is theoretical and experiential knowledge learned from studying and working in mathematics education. The focus of MCK in TEDS-M was on the mathematics that the future teachers would be required to teach plus some content 2 or 3 years beyond that.

Because TEDS-M was an international study, the decision was taken to make use of the TIMSS content frameworks for Year 8 and Advanced (Mullis et al. 2005; Garden et al. 2006). The MPCK framework in TEDS-M was developed by the TEDS-M international team, after a review of the literature and was informed in part by the framework used by the Mathematics Teaching in the 21st Century Project (MT21) (Blömeke et al. 2008; Schmidt et al. 2011) which focused on middle school mathematics teacher preparation in six countries. The final version of the MPCK framework was arrived at following a critical review by international experts in the field.

The TEDS-M MPCK framework consists of three sub-domains.

Mathematical curricular knowledge:

knowing the school mathematics curriculum, establishing appropriate learning goals, identifying key ideas in learning programs, selecting possible pathways and seeing connections within the curriculum, knowing different assessment formats and purposes

Knowledge of planning for mathematics teaching and learning:

selecting appropriate activities, predicting typical students' responses, including misconceptions, planning appropriate methods for representing mathematical ideas, linking didactical methods and instructional designs, identifying different approaches for solving mathematical problems, choosing assessment formats and items

Enacting mathematics for teaching and learning:

explaining or representing mathematical concepts or procedures, generating fruitful questions, diagnosing responses, including misconceptions, analysing or evaluating students' mathematical solutions or arguments, analysing the content of students' questions, responding to unexpected mathematical issues, providing appropriate feedback 


\section{Measuring Teacher Knowledge in TEDS-M}

The TEDS-M study measured knowledge found 'in the mind', not that 'in the body' as seen and found 'in our practices' (Connelly and Clandinin 1988). So, unlike the study by Huckstep et al. (2003), there was not the opportunity in TEDS-M to observe how the mathematics content knowledge of future primary teachers was enacted in practical teaching during school-based placements.

In TEDS-M, content knowledge was assessed by a combination of simple and complex multiple-choice items, together with short and extended constructed response items. Scoring guides for the constructed-response items were refined using responses from the field trial and for most extended constructed-response items, partial credit could be awarded.

\section{Short activity for the audience}

In order to sketch the difference between MCK and MPCK items, selected MCK and MPCK examples covering a range of attributes from the released TEDS-M item pool were presented to the audience including item statistics. The audience was invited to participate in providing "informed answers" to the items presented. Their answers were then contrasted with those obtained in the TEDS-M study by using "percent correct" information.

The total score points for each future teacher were analyzed using item response theory (Wu et al. 2007). This enabled four scales for knowledge for teaching mathematics to be constructed: MCK and MPCK for both primary and secondary. Tables and charts were created showing the distribution of country scale scores by program group.

Six "anchor points" were defined and described, two for each MCK scale and one for each MPCK scale. This enabled the achievement of future teachers in each program group to be described against the anchor points. It is hoped that these will provide useful benchmarks for future work. An example of the primary MPCK anchor point follows.

\section{Primary MPCK Anchor Point}

Future primary teachers who scored at this anchor point were generally able to recognize the correctness of a teaching strategy for a particular concrete example, and to evaluate students' work when the content was conventional or typical of primary grades. They were likely to identify the arithmetic elements of single-step story problems that influence their difficulty. Although future primary teachers at the primary MPCK anchor point were likely to be able to interpret some students' work, their responses were often unclear or imprecise. In addition, future teachers at the anchor point were unlikely to use concrete representations to support students' learning or to recognize how a student's thinking is related to a particular algebraic representation. They generally were unlikely to understand some measurement or probability concepts needed to reword or design a task. These future teachers also were unlikely to know why a particular teaching strategy made sense, if it would always work, or whether a strategy could be generalized to a larger class of 
problems. They were unlikely to be aware of common misconceptions or to conceive useful representations of numerical concepts.

For the 15 countries whose data could be analyzed, nine of the 21 program types across the four defined program groups had the majority of their future teachers at or above this anchor point on the MPCK scale. In some cases, items worth two score points (partial credit items) were able to measure levels of knowledge above and below anchor points. An example of this is item MFC410 ${ }^{3}$ shown in Fig. 1.

Future teachers at the primary MPCK anchor point were able to achieve partial credit ( 1 out of a maximum of two score points) with a probability of at least 0.7 on this

\section{MFC410}

Imagine that two <primary $>$ students in the same class have created the following representations to show the number of teeth lost by their classmates.

[Mary] drew pictures of her classmates on cards to make this graph.

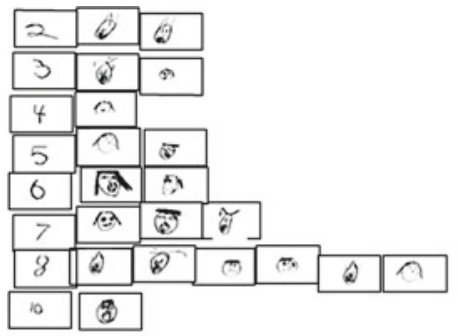

[Sally] cut out pictures of teeth to make this graph.

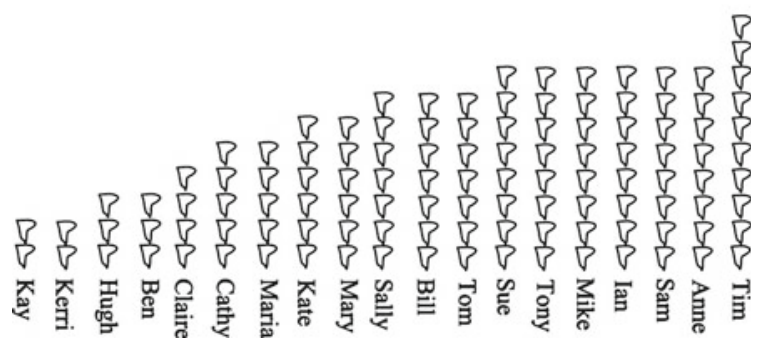

From a data presentation point of view, how are the representations alike and how are they different?

Alike:

Different:

Fig. 1 Item MFC410, primary MPCK - sub-domain Enacting, data, two score points

3 Alejandra Sorto, formerly of Michigan State University, is acknowledged for this item. 
Table 1 Scoring guide for MFC410

\begin{tabular}{|c|c|c|}
\hline Code & Response & Item: MFC410 \\
\hline & \multicolumn{2}{|c|}{ Correct response } \\
\hline \multirow[t]{2}{*}{20} & \multicolumn{2}{|c|}{$\begin{array}{l}\text { Responses that indicate how the representations are alike AND how they are } \\
\text { different } \\
\text { 'Alike' examples } \\
\text { - They both show the same data/same number of teeth lost } \\
\text { - They are both pictorial representations } \\
\text { - They are both forms of bar graphs } \\
\text { - They are both skewed in the same direction } \\
\text { 'Different' examples } \\
\text { - Mary has grouped the data/done a frequency tally whereas Sally has not } \\
\text { - In Mary's graph each bar or column represents the number of teeth lost, } \\
\text { whereas in Sally's graph each column or stack represents a student } \\
\text { - Mary's graph is categorized by the number of teeth lost whereas Sally's is } \\
\text { person by person }\end{array}$} \\
\hline & \multicolumn{2}{|c|}{ Partially correct response } \\
\hline 10 & \multicolumn{2}{|c|}{$\begin{array}{l}\text { The 'alike' description is acceptable but the 'different' description is not } \\
\text { acceptable, trivial or is missing } \\
\text { 'Alike' example } \\
\text { - They both show the same number of teeth lost } \\
\text { 'Different' example } \\
\text { - Mary's is easier to comprehend than Sally's }\end{array}$} \\
\hline \multirow[t]{2}{*}{11} & \multicolumn{2}{|c|}{$\begin{array}{l}\text { The 'different' description is acceptable but the 'alike' description is not } \\
\text { acceptable, trivial or is missing } \\
\text { 'Alike' example } \\
\text { - They both made graphs about teeth (Trivial) } \\
\text { 'Different' example } \\
\text { - Sally made a column for each student whereas Mary made a column for } \\
\text { each number of teeth lost }\end{array}$} \\
\hline & \multicolumn{2}{|c|}{ Incorrect response } \\
\hline 70 & \multicolumn{2}{|c|}{$\begin{array}{l}\text { Responses that are insufficient or trivial } \\
\text { 'Alike' examples } \\
\text { - They are both graphs } \\
\text { - Both graphs are about teeth } \\
\text { 'Different' examples } \\
\text { - Mary used numbers, Sally didn't } \\
\text { - Mary's is hard to read, Sally's is easier }\end{array}$} \\
\hline 79 & \multicolumn{2}{|c|}{$\begin{array}{l}\text { Other incorrect (including crossed out, erased, stray marks, illegible, or off } \\
\text { task) }\end{array}$} \\
\hline 99 & \multicolumn{2}{|c|}{ Non-response (blank) } \\
\hline
\end{tabular}


item. Only future teachers well above the anchor point were able to achieve full credit on this item. Twenty-nine percent $(29 \%)$ of the international sample of future teachers achieved full credit on this item and another $37 \%$ were able to achieve partial credit.

The following Table 1 shows the scoring guide for MFC410. On this item, for the international sample, $29 \%$ were awarded full credit, $37 \%$ partial credit, and $23 \%$ no credit. Eleven percent $(11 \%)$ of the international sample of future teachers chose not to respond. The future teachers who achieved partial credit found it harder to say how the representations were different $(6 \%)$ than how they were alike $(31 \%)$.

This work is described in more detail in recent TEDS-M publications (Senk et al. 2012; Tatto et al. 2012; Tatto 2013).

\section{Views from Audience Representatives}

The chair asked two Audience representatives to respond to two questions: "Is what TEDS-M measured valued by the mathematics education community (with a particular focus on the MPCK items)? How well has TEDS-M contributed knowledge to the field?"

Maitree Inprasitha (Thailand) stressed that before TEDS-M, most education faculties in Thailand provided only mathematics content courses (MCK) to future teachers. Now education faculties have started incorporating the idea of MPCK into teacher preparation curriculum. More recently, the Khon Kaen University received a grant to create a network among education faculties in order to redefine courses for future teachers who are majoring in mathematics education. Through this network, mathematics education faculty staff attend seminars and workshops hosted by the education faculty of Khon Kaen university.

Ildar Safuanov (Russia) indicated extensive research arising from TEDS-M in his country. Although Russia has strong MCK and MPCK results, research looks for fields where future teachers have difficulties (e.g., in constructing different interpretations of theoretical contents) in order to achieve improvements. Research also shows that there is a relationship between the quality of education of future teachers and their attitudes to teaching mathematics (e.g., related to an orientation on conceptual models and cognitive-constructivist approaches to teaching mathematics).

\section{Teacher Education and Quality: The Performance of Taiwan in an International Context}

\section{Becoming a Teacher in Taiwan}

Teaching in Taiwan is attractive in terms of income, working hours, career development opportunities, and job security. As a result, candidates face rigorous evaluation and serious competition throughout the process of becoming a teacher. 
Future teachers must obtain a bachelor's degree, complete the initial teacher education curriculum, and finish a practicum before they are evaluated in the yearlyheld, national-common teacher qualification assessment. The average passing rates of the qualification assessments for the years of 2007-2010 was 67.4\%.

To get a tenure teaching position, qualified teachers must also undergo a public, competitive, on-site-screening process administered by the school district or individual schools. The screenings are not held only for future teachers, but for all the practicing teachers who want to change schools. The average pass rates of the screenings across the country for the recent years 2007-2010 at the primary, lower secondary and upper secondary levels were 3.5, 11.9, and $6.5 \%$, respectively (Hsieh et al. 2012a). Regarding the future teachers, the average rates of employment for tenure teaching positions for 2007-2010 were lower than $3.4 \%$ for the primary level and $20.2 \%$ for the secondary level.

\section{What Taiwan Learned from TEDS-M on Teaching Knowledge}

As a participating country in TEDS-M, Taiwan intended to examine how future teachers performed and what the weaknesses and strengths of teachers were on teaching knowledge as compared to other countries. The results of MCK and MPCK achievement for future teachers, especially at the primary level, challenged the expectations of Taiwanese scholars in two areas. First, Taiwan ranked number one in performance. Second, Taiwan's percentages of correct answers for some primary items with low-level of difficulty were low.

In Taiwan, future teachers are expected to be knowledgeable and to master the concepts and skills on the field they intend to teach. It is expected that at least $80 \%$ (if not $100 \%$ ) of future teachers should provide correct answers for any item at their teaching level. However, Taiwan's data showed that, in the lower secondary-level study, $30 \%$ of MCK and $33 \%$ of MPCK items did not meet the desired $80 \%$ threshold. For the primary-level study, $36 \%$ of MCK and $83 \%$ of MPCK items did not achieve the $80 \%$ threshold. For the type of thought-oriented mathematical competence primary-level items, ${ }^{5}$ a high rate of $70 \%$ of items did not reach the $80 \%$ threshold. These results are a strong warning for the Taiwanese teacher education system.

\footnotetext{
${ }^{4}$ People may attend many screenings, so the actual rates of people who pass the screenings should be higher than these data.

5 This is a type of MCK that contrasts with another MCK-type: content-oriented mathematical competence. For more information concerning this section, see the relevant article by Hsieh et al. (2012b).
} 


\section{Why Taiwan Performed Well}

The Taiwan TEDS-M team was interested in analyzing how Taiwanese future teachers performed for MCK items with respect to different curricular levels. For this analysis, TEDS-M knowledge items were classified according to four curricular levels: primary, lower secondary, upper secondary or tertiary. The results showed that, in comparison to all participating countries, Taiwan demonstrated a unique pattern in the lower secondary-level study. As shown in Fig. 2, the pattern exhibited in Taiwan was high achievement with respect to the percentage of correct answers for items from primary, lower secondary, and upper secondary levels, but a sharp decline in percent correct on the tertiary level items. Singapore, which demonstrated performance similar to Taiwan for TIMSS, showed MCK achievement patterns different from those for Taiwan. Singapore, Germany, and Switzerland did not show achievement on primary-level MCK items as high as Taiwan but did show a sharp decline from primary to upper secondary levels. For all other countries (except for Taiwan, Singapore, Germany, and Switzerland), MCK achievement remained approximately the same from secondary to tertiary levels. Since Taiwanese lower secondary-level teacher education programs emphasize mostly tertiary-level mathematics (but do not cover primary-level mathematics), these data show that one of the reasons Taiwan performed better in MCK is that it recruits high-achieving students for secondary teacher education programs.

This idea also explains why Taiwan performed well in MPCK for the lower secondary-level study. Mathematical concepts applied for almost all MPCK items appear in the lower secondary-level, a level in which Taiwan excelled.

For the primary-level study, future Taiwanese teachers achieved high results for primary-level MCK items, lower secondary- and upper secondary-level items (see Fig. 3).

This result may demonstrate that Taiwan recruits high-achieving students for primary teacher education programs. However, a question remains as to why
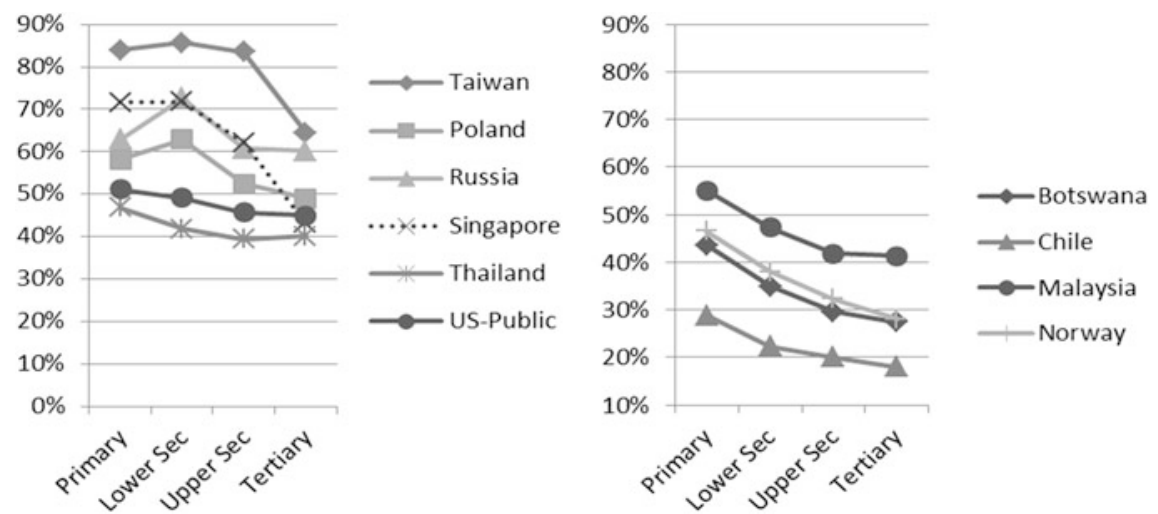

Fig. 2 Percentage of correct answers for MCK items across different levels in the lower secondary-level study for certain countries 

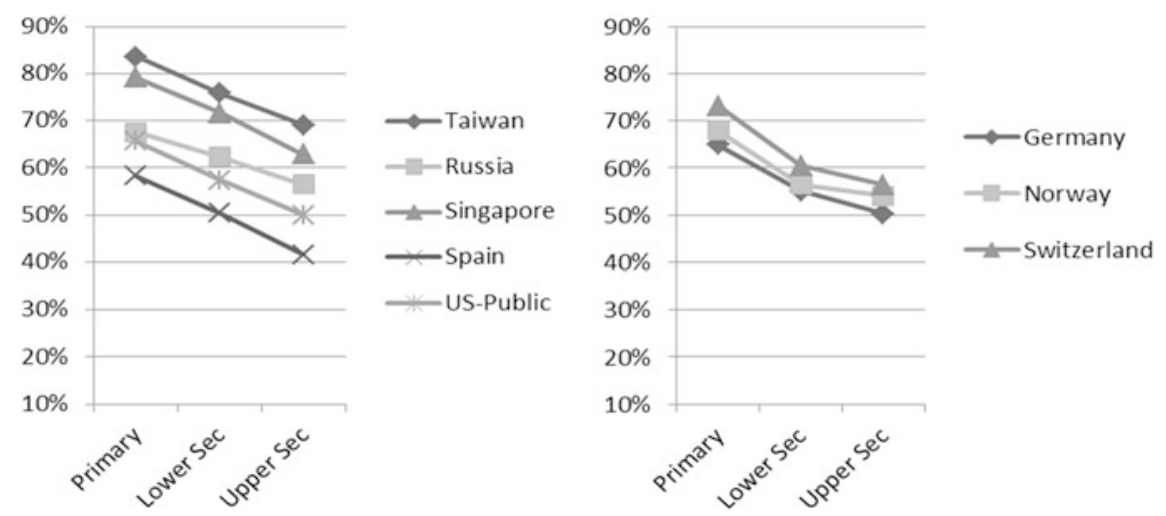

Fig. 3 Percentage of correct answers for MCK items across different levels in the primary-level study for certain countries

Singapore, which performed worse on the MCK than Taiwan, achieved results similar to Taiwan for the MPCK test. Further research is required to examine factors influencing relevant knowledge achievements.

Other TEDS-M data show that Taiwan may have demonstrated superior performance, especially in the lower secondary-level, because of the following reasons: Taiwan teaches more topics in both school- and tertiary-level mathematics than other countries, and future Taiwanese teachers have increased opportunities to perform challenging problems (thought-oriented). This finding is consistent with findings from analyses of relationships between Opportunity to Learn (OTL), MCK, and MPCK (Hsieh et al. 2012a).

\section{Short activities related to single-item performance}

The following questions were posed to the audience.

Example 1: (a lower secondary-level item)

$$
\text { Let } A=\left[\begin{array}{ll}
p & q \\
r & s
\end{array}\right] \text { and } B=\left[\begin{array}{ll}
t & u \\
v & w
\end{array}\right] \text {. Then } A \otimes B \text { is defined to be }\left[\begin{array}{ll}
p t & q u \\
r & s w
\end{array}\right] \text {. }
$$

Is it true that if $A \otimes B=0$, then either $A=0$ or $B=0$ (where $O$ represents the zero matrix)? Justify your answer.

The operation defined in Example 1, MFC814, ${ }^{6}$ a tertiary-level MCK item, is not taught in relevant courses. To correctly answer this problem, a testtaker must observe the relationships between mathematical objects, devise formal or informal mathematical arguments, and transform heuristic arguments into valid proofs.

${ }^{6}$ The Knowledge of Algebra for Teaching (KAT) project, Michigan State University, is acknowledged for item MFC814. 
Question 1: What percentage of future mathematics teachers at the secondary level can answer this item correctly in your country?

Example 2: (a lower secondary-level item)

\section{A mathematics teacher wants to show some students how to prove the quadratic formula.}

Determine whether each of the following types of knowledge is needed in order to understand a proof of this result.

\section{Check one box in each row}

Needed Not needed
A. How to solve linear equations.

$\square_{1} \quad \square_{2}$
B. How to solve equations of the form $x^{2}=k$, where $k>0$. $\square_{1} \square_{2}$
C. How to complete the square of a trinomial.
D. How to add and subtract complex numbers. $\square_{1} \square_{2}$
$\square_{1} \quad \square_{2}$

Example 2, MFC712, is an MPCK item concerning a formal approach for teaching the quadratic formula. Option $\mathrm{C}$ is considered necessary to understanding a proof of the formula.

Question 2: In which of the following situations will future teachers in your country know that option $\mathrm{C}$ is necessary? Answer Yes or No to each.

- If they know how to prove the quadratic formula and attempt to prove it when answering this item.

- If they know the pre-requisites for learning how to prove the quadratic formula.

- If they have watched a teacher teaching approaches for proving the quadratic formula.

- If they have had experience teaching how to prove the quadratic formula.

- If they have been taught by faculty in their teacher education programs how to demonstrate the quadratic formula.

Example 3: (a primary-level item)

How many decimal numbers are there between 0.20 and 0.30 ?
A. 9
B. 10
C. 99
D. An infinite number

Check one box.

A special feature of Example 3, MFC304, ${ }^{7}$ is that 0.2 is expressed as 0.20 .

Question 3: At what grade do teachers teach the addition of decimals with three digits in your country?

\footnotetext{
7 Item MFC304 is one of a pool of items developed for TEDS-M by Doug Clarke, Peter Sullivan, Kaye Stacey, Ann Roche, and Ray Peck, Melbourne, Australia.
} 
Discussion of other MCK and MPCK items can be found in an article by Hsieh et al. (2012b).

\section{Views from Audience Representatives}

After a short exchange with the audience, the chair asked two Audience representatives to "describe any interventions that have been undertaken in Chile and Norway as a consequence of disappointing TEDS-M results."

Liv Sissel Gronmo (Norway) stressed that although there was disappointment with the results, there have been few interventions so far. In particular, concerning the problem that future teachers do not have the necessary competence in mathematics, no measures have been taken so far. On the contrary, a recent change in teacher education has expanded the amount of general pedagogy which seems to be a step in the wrong direction.

María Leonor Varas (Chile) reported that TEDS-M results had-after a first shock - a distinguishable impact in Chile at different levels. For example, it accelerated decisions and deepened interventions that were in the process of implementation (e.g., outcome standards for teacher preparation programs and entrance examinations for teachers). It also led to an increased engagement of mathematicians in teacher preparation in collaboration with mathematics educators (e.g., jointly developing standards for teacher preparation as well as preparing books and materials to support its implementation).

\section{Research in Teacher Education and TEDS-M: International Findings and Implications for Future Policy Research}

Research has begun to advance our understanding of the knowledge considered most important for school mathematics teaching (e.g., Baumert et al. 2010; Hill et al. 2007; Schmidt et al. 2011; Tatto 2008; Tatto et al. 2010). For more than a decade, recommendations from relevant societies and expert groups have emphasized that future teachers of school mathematics need to develop a deep understanding of the mathematics they will teach (Conference Board of Mathematical Sciences 2001), and that to be successful "... mathematics teachers need preparation that covers knowledge of mathematics, of how students learn mathematics and of mathematical pedagogy" (National Research Council 2010, p. 123; Education Committee of the EMS 2012). Importantly for our discussion today are calls to collect "... quantitative and qualitative data about the programs of study in mathematics offered and required at teacher preparation institutions ... to improve understanding of what sorts of preparation approaches are most effective at developing effective teachers" (National Research Council 2010, p. 124). In this 
session, we will present some of the challenges involved in doing research in teacher education, the main findings that are emerging from the study, and plans for future research including a new study of novice mathematics teachers.

To recap, the overall goal of TEDS-M was to study in a group of countries how primary and secondary school mathematics teachers learn to teach subject matter content effectively to a wide variety of students as a result of their preparation programs. This comparative approach to exploring teacher education and its influence cross-nationally helped us to understand the combination of teacher education policies, learning opportunities, and levels of mathematics knowledge that future teachers reach in those countries where pupils show high mathematics achievement vis-à-vis those who do not. As we have said in previous articles, the intent of TEDS-M is to replace myths about when, what, and how teachers learn, with facts and conclusions backed by rigorous research (Tatto et al. 2011).

\section{Methods}

The most important challenges we encountered were methodological such as the sampling, the instrument development, and, given the diversity of programs we encountered, the approaches to describe the results. TEDS-M used comparative and survey research methods to produce correlational analyses. Original data were collected through the examination of policy documents; assessments of mathematics teaching knowledge; and questionnaires. TEDS-M implemented a two-stage sampling design: (a) selected samples representative of the national population of institutions offering initial teacher education to the target populations; (b) all programs in those institutions were included in the survey; (c) within institutions (and programs), samples of educators and of future teachers were surveyed. Samples had to reach the rigorous IEA sampling standards. Sampling errors were computed using balanced half-sample repeated replication (Fay 1989; Lohr 1999; McCarthy 1966; Tatto et al. 2012). The development of anchor points to interpret the knowledge scores in a meaningful way represented both a challenge and an important step forward in teacher education research. Anchor points can assist teacher preparation programs worldwide to establish benchmarks of performance for their graduates using TEDS-M assessments and analyses. These assessment tools were developed collaboratively and represent meaningful international standards (Tatto et al. 2012).

\section{Data Sources}

Policy and context data were collected using country reports, questionnaires, and interviews. TEDS-M conducted (a) surveys of the teacher education institutions using an institutional program questionnaire; (b) surveys of educators and mentors of future teachers in the institutions using a teacher educator questionnaire; and (c) 
surveys of future teachers in the sampled institutions. Questions on future teacher knowledge of mathematics and mathematics pedagogy were investigated via assessments developed for that purpose.

\section{Results}

The results of our study are presented in detail in the TEDS-M international report: Policy, Practice, and Readiness to Teach Primary and Secondary Mathematics in 17 Countries (Tatto et al. 2012), which is available for download from the TEDS-M webpage http://teds.educ.msu.edu/, or from the IEA webpage at http://www.iea.nl3.

For this presentation, we will only briefly highlight the key international findings from the mathematics knowledge assessments at the primary and lower secondary levels and discuss patterns in the organization of teacher preparation programs that indicate promising directions for policy.

Tables 2 and 3 show the descriptive statistics for mathematics content knowledge (MCK), by program group for the future teachers participating in the study at the primary and lower secondary levels. The tables show a key analysis strategy employed in TEDS-M: that is the way results were presented by "program groups" in order to cater for the different structures of teacher education systems. Table 2 reveals the variation in MCK scores across and within program groups. Given the international mean set at 500 and the standard deviation at 100 it can be seen that the difference in mean MCK scores between some countries, even in the same program group, was between one and two standard deviations. Here it will be helpful to illustrate the use of the anchor points - see above - to interpret TEDS-M results. In the high-scoring countries within each program group, the majority of future teachers had scores at or above the higher MCK anchor point. Differences between countries within program groups tended to be larger among the secondary groups (Table 3) than among the primary groups (Table 2). The results in the United States of America illustrate these differences.

Table 2 shows that in the USA more than $90 \%$ of future primary teachers reach Anchor Point 1, but only $50 \%$ reach Anchor Point 2, whether generalists or specialists; this places the USA below Taiwan, Singapore, and Switzerland in Group 2: primary generalists, and well below Poland, Singapore, Germany, and Thailand in Group 4: primary specialists. Table 3 shows the results of the secondary groups. Close to $70 \%$ of the USA teachers do not even reach Anchor Point 1 in Group 5: lower secondary teachers preparing to teach to Grade 10, placing them below Singapore, Switzerland, Poland, Germany, and Norway. USA future teachers, however, do better in the program Group 6: lower and upper secondary teachers prepared to teach Grade 11 and above in reaching Anchor Point 1, yet they still score well below the future teachers from Taiwan, Singapore, Germany, and the Russian Federation. While in all of these other countries more than $60 \%$ of future teachers reach Anchor Point 2, more than $55 \%$ of USA future teachers fail to reach the same benchmark. 


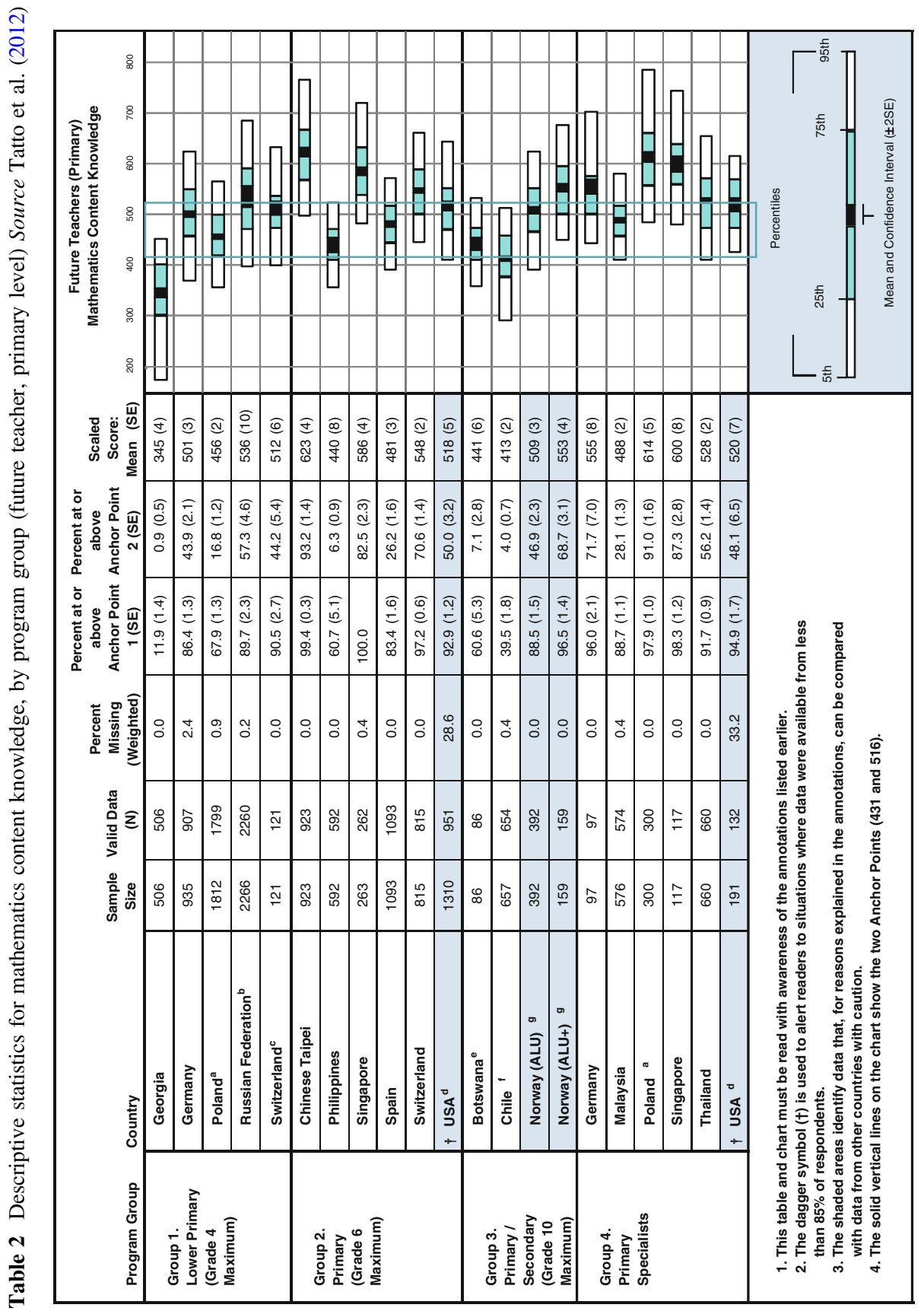




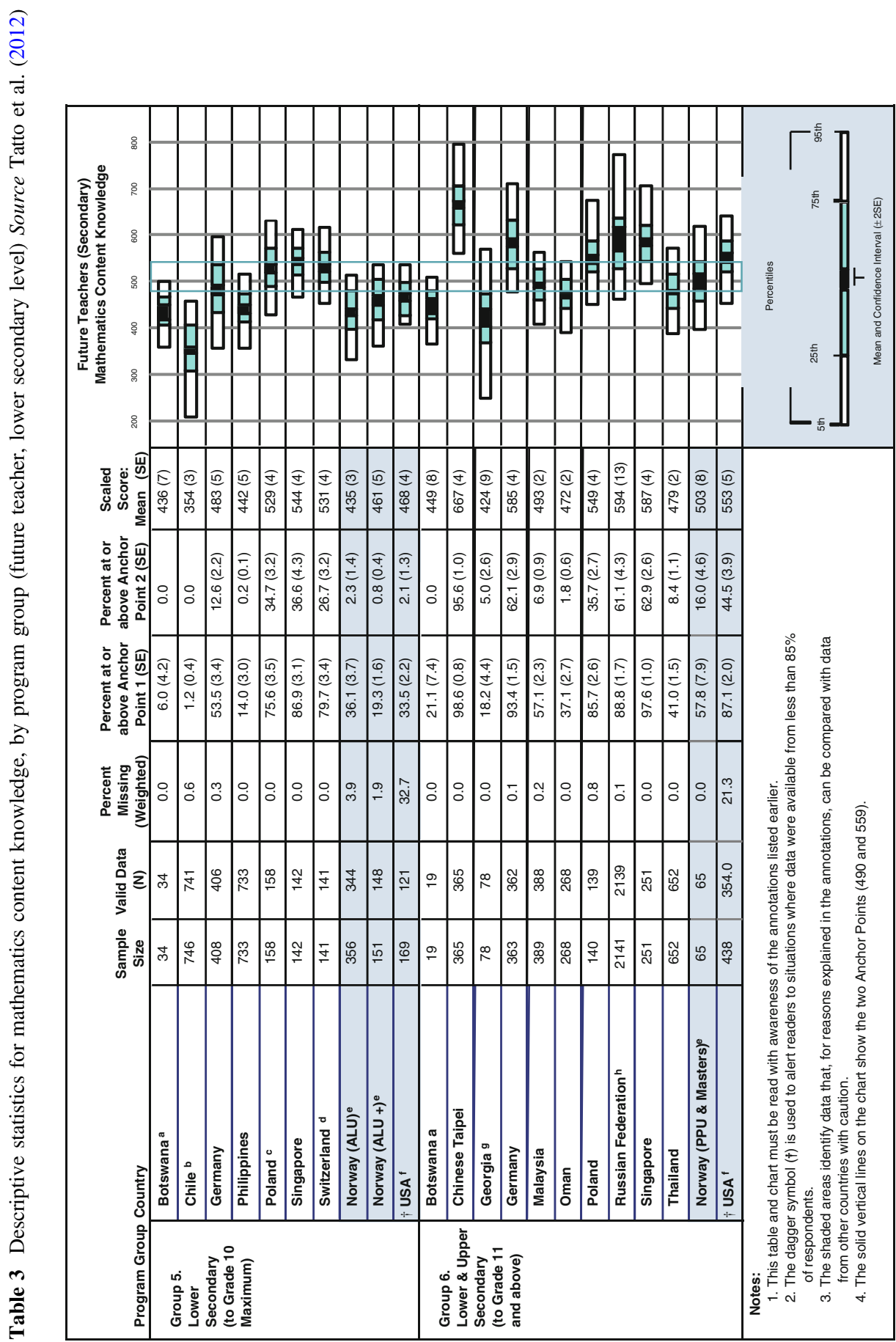


What may help explain these results? Our study shows that the design of teacher education programs and curricula content and orientation may have substantial effects on the level of knowledge that future teachers are able to acquire. In general, programs where future teachers are more successful in our assessments have rigorous standards in selecting those who enter the program, they have a demanding and sequential (versus repetitive) university and school mathematics curriculum, frequent formative evaluations (written and oral), and stringent graduation requirements. A conceptual, problem solving, and active learning orientation seems to characterize the views of mathematics among those future teachers who score higher in our assessments, likely reflecting the way they themselves learned mathematics and the views that their programs espouse (Tatto et al. 2012; Tatto et al. in press).

What could be some of the policy implications emerging from TEDS-M? Teacher education programs can increase their effectiveness by selecting future teachers according to their characteristics (e.g., previous school performance) and strengthening formative and summative evaluation as they progress through their program. In fact previous performance in school, gender and socioeconomic status are characteristics that seemed to explain in some degree the knowledge that future teachers demonstrate at the end of their formal initial teacher education (Tatto et al. in press).

A general conclusion of our analysis is that future teachers, who did well in their previous schooling, and specifically in high school, perform better in our mathematics knowledge for teaching assessments (Tatto et al. in press). In all countries, opportunities to learn university level mathematics and mathematics of the school curriculum, and reading research on teaching and mathematics were related to future teachers' knowledge as measured in our assessments. The more traditional view of mathematics as a finished product has given way to a more contemporary view of mathematics as a process of inquiry (Ernest 1989, p. 250), and to the idea that mathematics is better learned through a conceptual and inquiry-based form of learning. In general, successful programs seemed to be more coherently organized around the idea of what effective teachers need to know (Tatto et al. in press).

For primary programs, the most important positive influence of teacher education on mathematics knowledge for teaching is the opportunity to learn school level mathematics, specifically in the areas of function, probability, and calculus (Tatto et al. in press). Another important yet negative association with knowledge as measured by our assessment was found among future teachers who as a group hold the exclusive view that can be summarized as "mathematics is a collection of rules and procedures that prescribe how to solve a problem". This is a view that stands in contrast with the more accepted view, supported by cognitive science research on learning that, "in addition to getting a right answer in mathematics, it is important to understand why the answer is correct" and that in addition to learning basic facts, "teachers should allow pupils to figure out their own ways to solve a mathematical problem." While the first is a view that may be espoused by teacher education programs, it could also be a "naïve view" held by future teachers based on 
commonly held "cultural norms" and which remains unchallenged and unchanged by their program. In other words, the program may end up reinforcing traditional ways of teaching and learning, already acquired by future teachers in their own schooling (Tatto 1999).

For secondary programs the most important influence on knowledge for teaching is the opportunity to learn university level mathematics, specifically geometry, and the opportunity to read research in teaching and learning (Tatto et al. in press). As in the primary programs the exclusive view that "mathematics is a collection of rules and procedures that prescribe how to solve a problem" had a negative association with performance in our assessment.

One conclusion of this study is that teacher education programs' quality of opportunities to learn - as measured by their association with high levels of mathematics teaching knowledge, coherence on program philosophy and approaches, and internal and external quality assurance and accountability mechanisms, are all features that seem to contribute to increased levels of mathematics knowledge for teaching among future teachers. While the TEDS-M study is limited in how much it can tell us about the effects of high quality teacher education on initial teaching practice, it provides the basis for the development of further inquiry into this unexplored yet essential question: what elements contribute to the development of high quality teachers?

A further study, FIRSTMATH, will attempt to answer this question. This is a study of novice teachers' development of mathematical knowledge for teaching and the influence of previous preparation, school context and opportunities to learn-onthe-job, on that knowledge. FIRSTMATH will explore the connections between initial teacher education and what is learned on the job as it concerns knowledge, skills, and curricular content; and the degree to which standards, accountability, and other similar mechanisms operate to regulate the support that beginning teachers of mathematics receive during their first years of teaching. For more information on TEDS-M and FIRSTMATH consult the following websites: http://teds.educ.msu. edu/ and http://firstmath.educ.msu.edu/.

\section{Views from Audience Representatives}

Finally, the chair asked two Audience representatives their view on "how mathematics (teacher) educators in their country value TEDS-M as a contribution to research."

Mellony Graven (South Africa) highlighted that her country did not participate in TEDS-M (but did in the preceding MT21 study), partially for cost reasons. In South Africa, many teacher educators are unaware of the study, and the local literature on mathematics (teacher) education shows little take up or mention of the study.

Deborah Loewenberg Ball (USA) stressed the importance of TEDS-M: it has advanced the international conversation about what it means to be mathematically well-prepared for teaching, it has raised questions about the degree to which 
common measures of mathematical knowledge for teaching can be developed, and it has made possible more common research about selection, education, and effects on initial teaching across countries.

The Panel closed with concluding words by the Panel members, expressing thanks to the IPC including the Panel-liaison Gabriele Kaiser (Germany) and the local organizers including Mi-Kyung $J u$ (South Korea) as the presider of the Panel.

Open Access This chapter is distributed under the terms of the Creative Commons Attribution Noncommercial License, which permits any noncommercial use, distribution, and reproduction in any medium, provided the original author(s) and source are credited.

\section{References}

Adler, J., Ball, D. L., Krainer, K., Lin, F.-L., \& Novotna, J. (2005). Mirror images of an emerging field: Researching mathematics teacher education. Educational Studies in Mathematics, 60(3), 359-381.

Anthony, G., \& Walshaw, M. (2009). Effective pedagogy in mathematics: Educational practices series, 19. International Academy of Education, International Bureau of Education \& UNESCO. Available online from the UNESCO website.

Baumert, J., Kunter, M., Blum, W., Brunner, M., Voss, T., Jordan, A., Klusmann, U., Krauss, S., Neubrand, M., \& Tsai, Y.-M. (2010). Teachers' mathematical knowledge, cognitive activation in the classroom, and student progress. American Educational Research Journal, 47(1), 133 180.

Blömeke, S. (2011). WYSIWYG: Von nicht erfüllten Erwartungen und übererfüllten Hoffnungen - Organisationsstrukturen der Lehrerbildung aus internationaler Perspektive. Erziehungswissenschaft, 43, 13-31.

Blömeke, S., Kaiser, G., Lehmann, R., \& Schmidt, W. H. (2008). Introduction to the issue on empirical research on mathematics teachers and their education. ZDM - The International Journal on Mathematics Education, 40(5), 715-717.

Conference Board of Mathematical Sciences (2001). The mathematical education of teachers (Vol. 2). Washington, DC: American Mathematical Society.

Connelly, F. M., \& Clandinin, D. J. (1988). Teachers as curriculum planners: Narratives of experience. New York, USA: Teachers College Press.

Education Committee of the EMS (2012). It is Necessary that Teachers are Mathematically Proficient, but is it Sufficient? Solid Findings in Mathematics Education on Teacher Knowledge. Newsletter of the European Mathematical Society, March 2012, Issue 83, 46-50.

Ernest, P. (1989). The impact of beliefs on the teaching of mathematics. In: Ernest, E. (Ed.), Mathematics Teaching: The State of the Art (pp. 249-254). New York, USA: Falmer Press.

Fay, R. E. (1989). Theoretical Application of Weighting for Variance Calculation. Proceedings of the Section on Survey Research Methods of the American Statistical Association, 212-217.

Fullan, M. (1993). Change forces. Probing the depths of educational reform. London: Falmer Press.

Garden, R., Lie, S., Robitaille, D. F., Angell, C., Martin, M. O., Mullis, I. V. S., et al. (2006). TIMSS Advanced 2008 assessment frameworks. Chestnut Hill, MA: Boston College.

Hattie, J. A. (2003). Teachers make a difference: What is the research evidence? Australian Council for Educational Research Annual Conference on: Building Teacher Quality.

Hill, H. C., Rowan, B., \& Ball, D. L. (2005). Effects of Teachers' Mathematical Knowledge for Teaching on Student Achievement. American Educational Research Journal, 42(2), 371-406. 
Hill, H. C., Sleep, L., Lewis, J. M., \& Ball, D. L. (2007). Assessing teachers' mathematical knowledge: What matters and what evidence counts? In F. K. Lester (Ed.), Second Handbook of Research on Mathematics Teaching and Learning (pp. 111-156). Charlotte, NC: Information Age.

Hsieh, F.-J., Lin, P.-J., \& Shy, H.-Y. (2012a). Mathematics teacher education in Taiwan. In Tso, T. Y. (Ed.), Proc. 36th Conf. of the Int. Group for the Psychology of Mathematics Education, Vol. 1 (pp. 187-206). Taipei, Taiwan: PME.

Hsieh, F.-J., Lin, P.-J., \& Wang, T.-Y. (2012b). Mathematics related teaching competence of Taiwanese Primary Future Teachers: Evidence from the TEDS-M. ZDM - The International Journal on Mathematics Education. DOI: 10.1007/s11858-011-0377-7 http://www. springerlink.com/content/074647770n574812/fulltext.pdf.

Huckstep, P., Rowland, T., \& Thwaites, A. (2003). Primary teachers' mathematics content knowledge: what does it look like in the classroom? Education-line database. Accessed 1 April 2012 < http://www.leeds.ac.uk/educol/documents/00002534.htm>

Krainer, K. (2011). Teachers as stakeholders in mathematics education research. In B. Ubuz (Ed.), Proc. 35th Conf. of the Int. Group for the Psychology of Mathematics Education, Volume 1 (pp. 47-62). Ankara, Turkey: Middle East Technical University.

Loewenberg-Ball, D., Blömeke, S., Delaney, S., \& Kaiser, G. (Eds.) (2012). Measuring teacher knowledge - approaches and results from a cross-national perspective. ZDM - The International Journal on Mathematics Education, 44(2). (See http://www.springer.com/education+\%26 +language/mathematics+education/journal/11858).

Lohr, L. S. (1999). Sampling: Design and Analysis. Pacific Grove, CA: Duxbury Press.

McCarthy, P. J. (1966). Replication: An Approach to the Analysis of Data from Complex Surveys. Vital and Health Statistics, Series 2, No. 14. Hyattsville, MD: National Center for Health Statistics.

Mullis, I. V. S., Martin, M. O., Ruddock, G. J., O’Sullivan, C. Y., Arora, A., \& Erberber, E. (2005). TIMSS 2007 Assessment Frameworks. Chestnut Hill, MA: Boston College.

National Research Council (2010). Preparing teachers: Building evidence for sound policy (Committee on the Study of Teacher Preparation Programs in the United States, Division of Behavioral and Social Sciences and Education). Washington, DC: National Academy Press.

Schmidt, W., Blömeke, S., \& Tatto, M. T. (2011). Teacher education matters. A study of middle school mathematics teacher preparation in six countries. New York, NY: Teachers College Press.

Senk, S. L., Tatto, M. T., Reckase, M., Rowley, G., Peck, R., \& Bankov, K. (2012). Knowledge of future primary teachers for teaching mathematics: An international comparative study, ZDM The International Journal on Mathematics Education. DOI: 10.1007/s11858-012-0400-7 http://www.springerlink.com/content/f881483261201gu4/

Shulman, L. S. (1986). Those who understand: Knowledge growth in teaching. Educational Researcher, 15(3), 4-14.

Tatto, M. T. (2008). Teacher policy: A framework for comparative analysis. Prospects: Quarterly Review of Comparative Education, 38, 487-508.

Tatto, M. T. (1999). The socializing influence of normative cohesive teacher education on teachers' beliefs about instructional choice. Teachers and Teaching, 5, 111-134.

Tatto, M. T. (Ed.) (2013, published in 2014). The Teacher Education and Development Study in Mathematics (TEDS-M). Policy, Practice, and Readiness to Teach Primary and Secondary Mathematics in 17 Countries: Technical Report. Amsterdam, The Netherlands: International Association for the Evaluation of Student Achievement.

Tatto, M.T., Lerman, S., \& Novotná, J. (2010). The organization of the mathematics preparation and development of teachers: A report from the ICMI Study 15. Journal of Mathematics Teacher Education, 13, 313-324.

Tatto, M. T., Rodriguez, M. C., \& Lu, Y. (in press). The Influence of Teacher Education on Mathematics Teaching Knowledge: Local Implementation of Global Ideals. In G. K. LeTendre \& A. W. Wiseman (Eds.), Promoting and Sustaining a Quality Teacher Workforce Worldwide. Bingley, United Kingdom: Emerald. 
Tatto, M. T., Schwille, J., Senk, S. L., Ingvarson, L., Rowley, G., Peck, R., Bankov, K., Rodriguez, M., \& Reckase, M. (2012). Policy, Practice, and Readiness to Teach Primary and Secondary Mathematics in 17 Countries. Findings from the IEA Teacher Education and Development Study in Mathematics (TEDS-M). Amsterdam, The Netherlands: International Association for the Evaluation of Student Achievement.

Tatto, M. T., \& Senk, S., Rowley, G., \& Peck, R. (2011). The Mathematics Education of Future Primary and Secondary Teachers: Methods and findings from the Teacher Education and Development Study in Mathematics. Journal of Teacher Education, 62(2), 121-137.

Wu, M. L., Adams, R. J., Wilson, M. R., \& Haldane, S. A. (2007). ACER ConQuest Version 2: Generalised item response modelling software [computer program]. Camberwell, Victoria: Australian Council for Educational Research. 